\title{
Laparoscopic hepatectomy for the treatment of hepatic alveolar echinococcosis
}

\author{
Li Wan ${ }^{1,2}$, Bo Ran ${ }^{1,3}$, Tuerganaili Aji ${ }^{1,3}$, Paizula Shalayiadang ${ }^{1,3}$, Tiemin Jiang ${ }^{1,3}$, Yingmei Shao ${ }^{1,3}$, and Hao Wen ${ }^{1,2, *}$ \\ ${ }^{1}$ Department of Hepatobiliary \& Hydatid, Digestive and Vascular Surgery Centre, First Affiliated Hospital of Xinjiang Medical \\ University, 830011 Urumqi, PR China \\ ${ }^{2}$ State Key Laboratory of Pathogenesis, Prevention and Treatment of High Incidence Diseases in Central Asia, Xinjiang Medical \\ University, 830011 Urumqi, PR China \\ ${ }^{3}$ Xinjiang Hydatid \& Hepatobiliary Surgery Medical Centre, 830054 Urumqi, PR China
}

Received 7 October 2020, Accepted 4 January 2021, Published online 13 January 2021

\begin{abstract}
Background: At present, laparoscopy is relatively mature as a minimally invasive technique, but there are few reports on this approach for the radical treatment of hepatic alveolar echinococcosis (AE). In this study, we aimed to evaluate the safety and feasibility of laparoscopic hepatectomy $(\mathrm{LH})$ for AE treatment. Results: A retrospective review of medical records obtained from 13 patients diagnosed with AE between January 2018 and December 2019 and treated with laparoscopic hepatectomy was conducted at the First Affiliated Hospital of Xinjiang Medical University. All patients $(n=13)$ underwent hepatic resection using laparoscopy and none were transferred to open surgery. The average duration of surgery was $285 \mathrm{~min}(145-580 \mathrm{~min})$. Intraoperative bleeding was $305 \mathrm{~mL}$ $(20-2000 \mathrm{~mL})$. The mean duration of postoperative catheterization was 6.9 days (3-21 days), and postoperative hospital stay was 7.2 days (4-14 days). No complication of Clavien-Dindo grade III or above occurred, except for the second patient with acute liver failure post-surgically. No recurrences or deaths were observed at 9-30 months of follow-up. Conclusions: Laparoscopic hepatectomy appears to be safe and effective in selected AE patients. The advantages of this technique for AE treatment need to be further compared with the classical open approach.
\end{abstract}

Key words: Alveolar echinococcosis, Laparoscopic hepatectomy, Minimally invasive.

Résumé - Hépatectomie laparoscopique pour le traitement de l'échinococcose alvéolaire hépatique. Contexte : À l'heure actuelle, la laparoscopie est relativement mature en tant que technique minimalement invasive, mais il existe peu de rapports sur cette approche pour le traitement radical de l'échinococcose alvéolaire hépatique (EA). Dans cette étude, nous avons cherché à évaluer la sécurité et la faisabilité de l'hépatectomie laparoscopique pour le traitement des EA. Résultats : Une revue rétrospective des dossiers médicaux obtenus auprès de 13 patients diagnostiqués pour EA entre janvier 2018 et décembre 2019 et traités par hépatectomie laparoscopique a été menée dans le premier hôpital affilié de l'Université médicale du Xinjiang. Tous les patients $(n=13)$ ont subi une résection hépatique par laparoscopie et aucun n'a été transféré en chirurgie ouverte. La durée moyenne de la chirurgie était de 285 min (145 à $580 \mathrm{~min})$. Le saignement peropératoire était de $305 \mathrm{ml}(20$ à $2000 \mathrm{ml})$. La durée moyenne du cathétérisme postopératoire était de 6,9 jours ( 3 à 21 jours) et l'hospitalisation postopératoire était de 7,2 jours (4 à 14 jours). Aucune complication de grade III ou supérieur (Clavien-Dindo) n'est survenue, sauf pour le deuxième patient présentant une insuffisance hépatique aiguë après la chirurgie. Aucune récidive ou décès n'a été observé à 9-30 mois de suivi. Conclusions : L'hépatectomie laparoscopique semble sûre et efficace chez certains patients atteints d'EA. Les avantages de cette technique pour le traitement des EA doivent être mieux comparés à l'approche ouverte classique.

\section{Introduction}

Hepatic alveolar echinococcosis (AE) is a chronic proliferative parasitic disease, with a poor natural prognosis due to its characteristic infiltrative growth [15]. It is reported that mortality in untreated or inadequately treated AE patients can

\footnotetext{
*Corresponding author: dr.wenhao@163.com
}

be as high as $90 \%$ after 10-15 years of diagnosis $[1,8,17]$. Therefore, the expert consensus is that patients with diagnosed $\mathrm{AE}$ should be given timely surgery or drug treatment $[4,5]$. To date, radical surgical resection has still been considered the main method of AE treatment, despite the increased interest in nonsurgical techniques $[1-3,7,9,11-14,16]$. In recent years, laparoscopic hepatectomy (LH) has been well accepted by patients since it is minimally invasive. Therefore, LH has 
been proposed for the treatment of $\mathrm{AE}$ and is used in clinical practice.

In this retrospective analysis, $13 \mathrm{AE}$ cases admitted to our centre from January 2018 to December 2019 were included to discuss the treatment outcomes of LH and propose initial possibly selective criteria.

\section{Patients and methods \\ Ethics statement}

All patients in this study provided written informed consent before surgery. This study was approved by the Ethics Committee of the First Affiliated Hospital of Xinjiang Medical University (No. 20200116-04).

\section{Patients}

A total of 13 patients (male: 6, female: 7) receiving LH were enrolled in this retrospective analysis. Eligible patients were those confirmed with AE lesions located within the halfliver by using colour doppler ultrasound (US) and computed tomography $(\mathrm{CT})$. In addition, the liver remnant was adequate $(\geq 40 \%)$. Finally, patients could tolerate a laparoscopic operation on the basis of their cardiac and pulmonary function. The exclusion criteria were as follows: patients' lesions have invaded important vessels of the hilum and/or patients have developed extra-hepatic distant metastasis.

\section{Operation}

The patients were in the supine position. Routine disinfection and draping were performed after the onset of anaesthesia. Next, a small incision of about $1.2 \mathrm{~cm}$ was made above the umbilicus and a Veress needle was placed. Subsequently, $\mathrm{CO}_{2}$ pneumoperitoneum was established, and intra-abdominal pressure was maintained in a range of $10-12 \mathrm{mmHg}$. Afterwards, an inspection hole was made at a position that was above the navel in order to introduce the laparoscope. On this basis, the lesion size, location and adhesion to the surrounding tissues were evaluated. Once the characteristics of lesions were clarified, the remaining four trocars were successively entered under the visualisation of a monitor. Operative procedures followed the steps described below. Step 1: the first hepatic portal was adequately separated from the peripheral tissues. Step 2: the diseased lobe was adequately separated from the peripheral tissues and organs by ultrasound scalpel. Step 3: the pre-cut liver line was marked on the liver tissue $1-2 \mathrm{~cm}$ away from the lesion with the coagulation hook. Step 4: after blocking the first hepatic portal vessels, the diseased lobe was resected using an ultrasound scalpel along the pre-cut liver line. In the presence of significant capillary haemorrhage, immediate haemostasis was carried out using a mono-polar electrocoagulation or ultrasound scalpel. Meanwhile, large blood vessels and bile ducts were closed using absorbable clips until total diseased liver was completely resected. Step 5: monopolar electrocoagulation was used for electrocauterisation of the hepatic wound surface. Re-examination was carried out to observe whether active bleeding and/or biliary fistula were present. Local surgical areas were covered using biological absorbable haemostatic gauzes. Step 6: the diseased liver lobe was placed into a sampling bag, and then the bag was extracted out from the abdominal wall through the extending subxiphoid incision. Step 7: a drainage tube was inserted around the surgical region.

\section{Results \\ Patient characteristics}

The characteristics of the 13 patients enrolled in our study are summarized in Table 1. According to the WHO-IWGE classification criteria, all 13 patients in our study belong to P1NOM0/P2NOM0 stages of hepatic AE. The mean age was 32.7 years (18-52 years). The mean BMI was $22.8 \mathrm{~kg} / \mathrm{m}^{2}$ $\left(18-33 \mathrm{~kg} / \mathrm{m}^{2}\right)$. None of the patients had clinical discomfort when they sought medical attention, except two patients who had dull pain in the right upper abdomen preoperatively. The serology results of all patients were positive, and the residual liver volume were adequate $(>40 \%)$ by preoperative imaging assessment. No patient had received albendazole treatment before surgery. Of note, the fifth patient was also found to have a $\mathrm{CE}$ cyst on the right liver lobe in addition to an $\mathrm{AE}$ lesion, and the $\mathrm{AE}$ lesion of the eleventh patient was located within the middle liver lobe (Fig. 1).

\section{Intraoperative conditions}

LH was successfully completed in all patients. The average operation duration was $285 \mathrm{~min}(145-580 \mathrm{~min})$, and the average blood loss was $305 \mathrm{~mL}(20-2000 \mathrm{~mL})$. Two patients were given blood transfusion due to excessive intraoperative bleeding and a long operating time. Seven patients has simultaneous laparoscopic cholecystectomy (LC) due to concurrent chronic cholecystitis. Interestingly, pathology examination results confirmed that the lesion was $\mathrm{AE}$ and there was no residual lesion at the resection margin (Table 2).

\section{Postoperative conditions}

All patients could walk and eat 1-3 days (mean: 1.2 days) after surgery. First flatus was found 1-3 days (mean: 1.7 days) after surgery. After surgery, drainage of the abdominal cavity was performed for 3-21 days (mean: 6.9 days) until no liquid was observed. The postoperative hospital stay lasted for 4-14 days (mean 7.2 days). Clinical symptoms of acute liver failure were observed in the second patient on the first postoperative day, and she was given treatment immediately. Fortunately, with positive treatment, her liver function gradually recovered and essentially returned to normal on the 7th postoperative day. On postoperative day 14, this patient met discharge criteria and was discharged with an abdominal drain, which was removed at a local hospital one week later. The seventh patient was also discharged with a drainage tube due to hydrops in the operation area. One week later, the effusion resolved spontaneously and then the drainage tube was removed in our hospital. All patients' incisions healed well without incision-related complications. No mortality was 
Table 1. Baseline information for 13 patients.

\begin{tabular}{|c|c|c|c|c|c|c|c|c|c|c|c|c|c|}
\hline \multirow[t]{2}{*}{ Case } & \multirow[t]{2}{*}{ Sex } & \multirow[t]{2}{*}{ Age } & \multirow[t]{2}{*}{ BMI } & \multirow{2}{*}{$\begin{array}{l}\text { Child- } \\
\text { Pugh }\end{array}$} & \multirow[t]{2}{*}{$\mathrm{ABZ}$} & \multicolumn{4}{|c|}{ Liver lesion } & \multirow[t]{2}{*}{ Serology } & \multirow[t]{2}{*}{ PHOAS } & \multirow[t]{2}{*}{ Sym } & \multirow{2}{*}{$\begin{array}{c}\text { Other } \\
\text { disease }\end{array}$} \\
\hline & & & & & & PNM & Loc & Size & Num & & & & \\
\hline 1 & $\mathrm{M}$ & 18 & 20 & $\mathrm{~A}$ & No & P1N0M0 & RPL & $8 \times 5$ & 1 & + & No & No & No \\
\hline 2 & $\mathrm{~F}$ & 52 & 26 & A & No & P2NOM0 & RL & $11 \times 8$ & 1 & + & Yes & No & Hypertension \\
\hline 3 & M & 33 & 21 & A & No & P1NOM0 & LLL & $14 \times 9$ & 1 & + & No & No & No \\
\hline 4 & $\mathrm{~F}$ & 42 & 22 & A & No & P2NOM0 & RL & $9 \times 7$ & 1 & + & No & No & No \\
\hline 5 & M & 19 & 19 & A & No & P1N0M0 & RAL & $4 \times 4$ & 1 & + & No & No & No \\
\hline 6 & M & 36 & 23 & A & No & P2NOM0 & RL & $11 \times 9$ & 1 & + & No & No & No \\
\hline 7 & $\mathrm{~F}$ & 22 & 22 & $\mathrm{~A}$ & No & P1NOM0 & RPL & $5 \times 5$ & 1 & + & No & No & No \\
\hline 8 & M & 30 & 18 & $\mathrm{~A}$ & No & P1N0M0 & LLL & $3 \times 2$ & 1 & + & No & No & No \\
\hline 9 & $\mathrm{~F}$ & 38 & 26 & A & No & P2NOM0 & LL & $7 \times 5$ & 1 & + & No & Dull pain & No \\
\hline 10 & $\mathrm{~F}$ & 33 & 19 & A & No & P1NOM0 & RAL & $4 \times 3$ & 1 & + & No & No & No \\
\hline 11 & F & 22 & 22 & A & No & P2NOMO & ML & $8 \times 7$ & 1 & + & No & Dull pain & No \\
\hline 12 & M & 28 & 33 & A & No & P1NOM0 & LLL & $10 \times 8$ & 1 & + & No & No & No \\
\hline 13 & $\mathrm{~F}$ & 52 & 26 & A & No & P1NOM0 & LML & $8 \times 4$ & 1 & + & Yes & No & No \\
\hline
\end{tabular}

RPL: right posterior lobe; RL: right lobe; LLL: left lateral lobe; RAL: right anterior lobe; ML: middle lobe; LL: left lobe; LML: left medial lobe. PHOAS: pre-operation history of abdominal surgery. PNM (WHO/IWGE [4]): P1: peripheral lesion without proximal vascular and/or biliary involvement; P2: central lesions with proximal vascular and/or biliary involvement of one lobe; N0: No regional involvement; M0: No metastasis. BMI: body mass index $\left(\mathrm{kg} / \mathrm{m}^{2}\right)$. ABZ: albendazole; Loc: location; Num: number; Sym: symptoms.
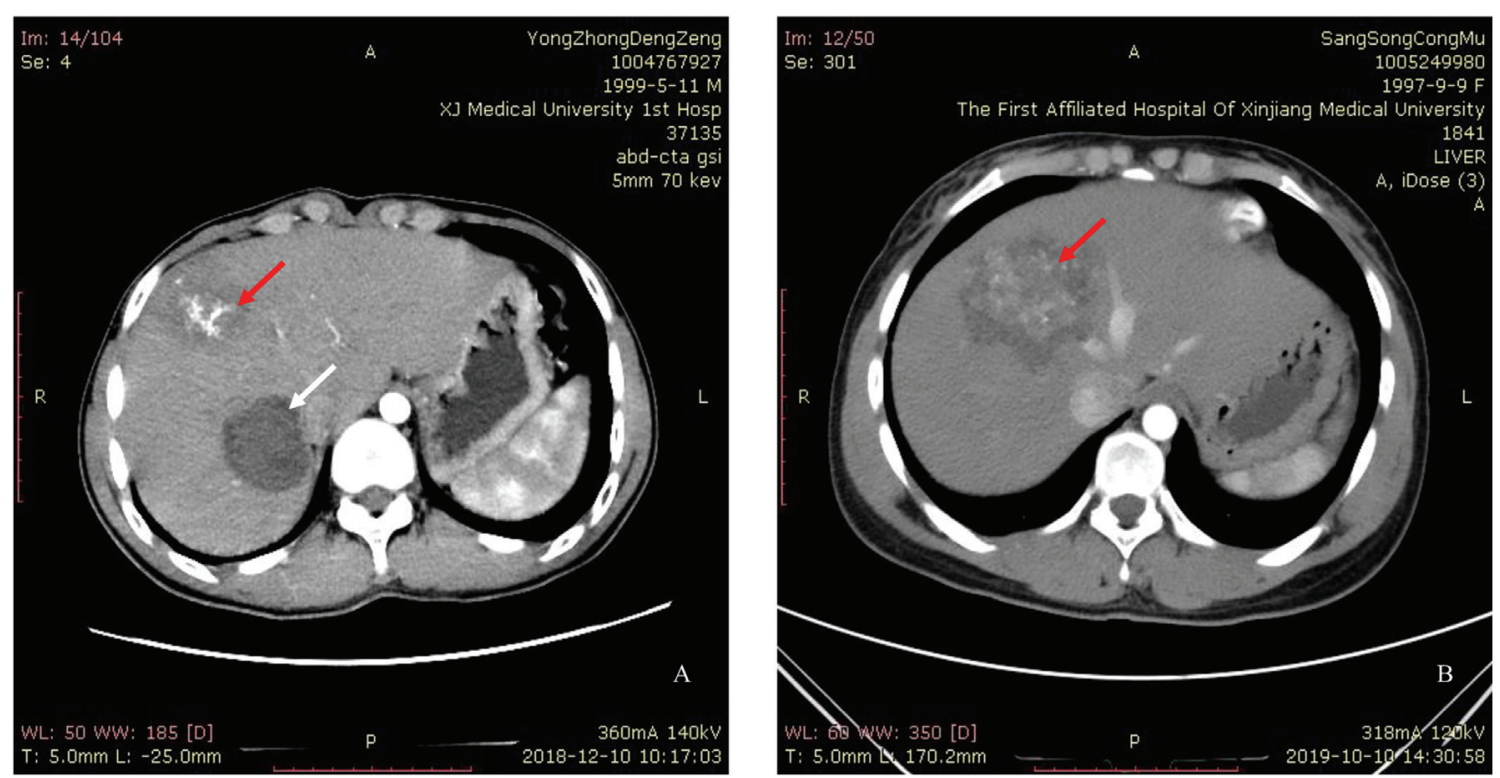

Figure 1. (A) An AE lesion located in the right anterior lobe of the liver (red arrow) and a CE cyst located in the right posterior lobe of the liver (white arrow). (B) The AE lesion is located in the middle liver lobe (red arrow).

reported during hospitalization. All patients were followed up. The average follow-up time was 15.7 months (9-30 months). During the follow-up period, no AE relapse was observed as revealed by US and/or CT in these patients (Table 3).

\section{Discussion}

Hepatic alveolar echinococcosis, also known as hepatic multilocular echinococcosis, is a rare parasitic disease caused by the larval stage of Echinococcus multilocularis parasitising the human liver $[16,17]$. Especially in the early and middle AE stages (P1NOM0/P2N0M0), it is particularly difficult to detect due to an absence of typical clinical symptoms. In addition, our team is not currently able to perform LH in most clinical AE patients because they are already in the advanced and/or terminal stage (P3 $\sim 4 \mathrm{NxMx}$ ) of the disease, in which lesions have invaded the important vessels of the hilum and/ or patients have developed extrahepatic metastasis. These reasons explain the small number of cases in the present study.

Unlike other benign and malignant liver diseases, AE lesions have unique characteristics: large size, infiltrative growth, and hard texture. These characteristics may bring some challenges in terms of intraoperative exposure and intraoperative haemostasis. The second patient in our study developed an acute decrease in liver function after surgery because of 


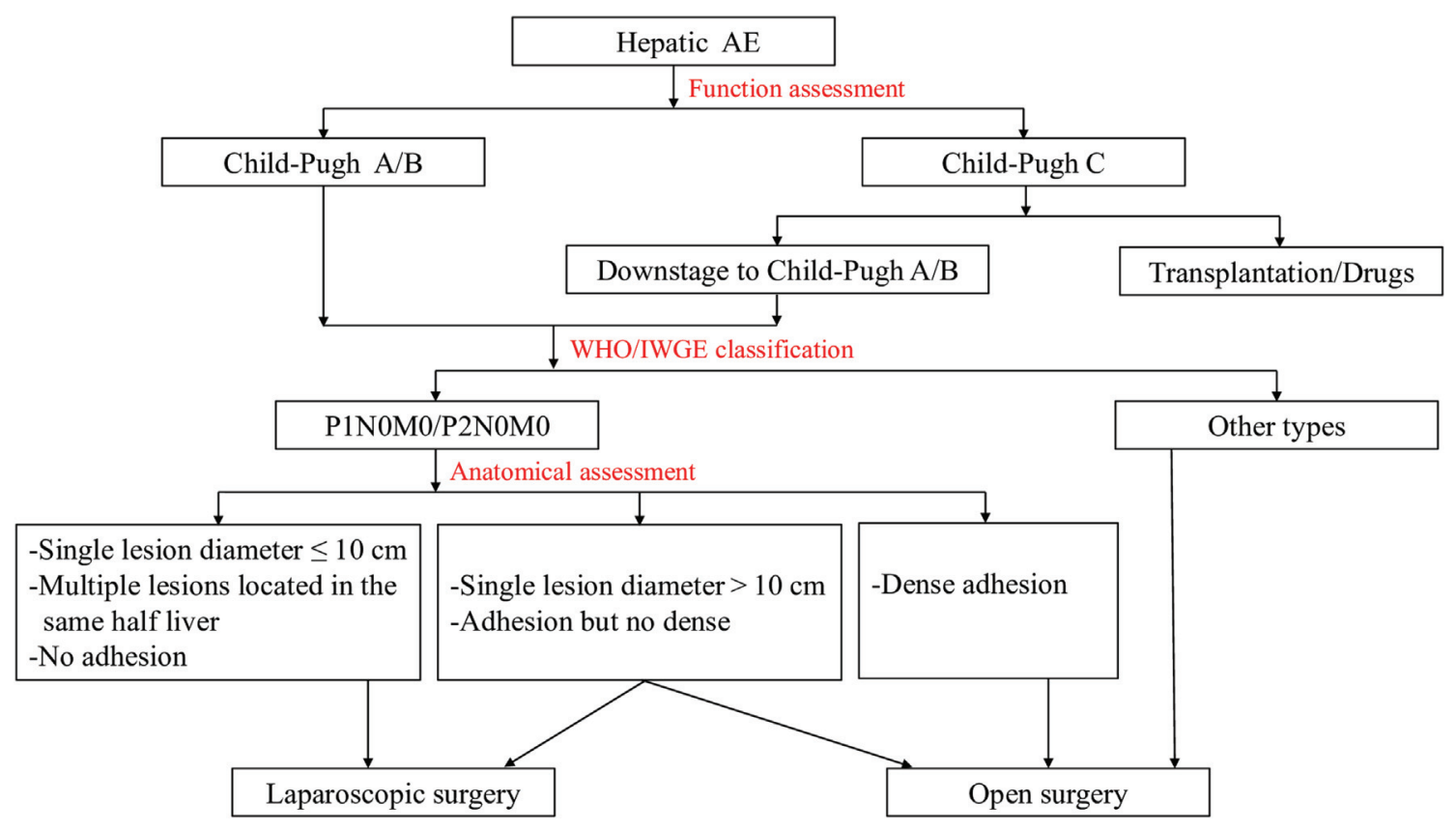

Figure 2. Treatment algorithms for hepatic alveolar echinococcosis.

Table 2. Operative parameters for 13 patients.

\begin{tabular}{|c|c|c|c|c|c|c|}
\hline \multirow[t]{2}{*}{ Case } & \multirow{2}{*}{$\begin{array}{c}\text { Date of operation } \\
(\text { yyyy } / \mathrm{mm} / \mathrm{dd})\end{array}$} & \multicolumn{4}{|c|}{ Operation } & \multirow[t]{2}{*}{ Details } \\
\hline & & Duration (min) & Bleeding $(\mathrm{mL})$ & Blood transfusion (units) & Residual lesions & \\
\hline$\overline{1}$ & 2018.02 .11 & 375 & 200 & 0 & $\mathrm{NO}$ & $\overline{L W R}+\mathrm{LC}$ \\
\hline 2 & 2018.05 .10 & 400 & 2000 & 3 & NO & $\mathrm{LRH}+\mathrm{LC}$ \\
\hline 3 & 2018.11 .14 & 285 & 100 & 0 & NO & LLLH \\
\hline 4 & 2018.12 .04 & 365 & 200 & 0 & NO & $\mathrm{LRH}+\mathrm{LC}$ \\
\hline 5 & 2018.12 .14 & 240 & 20 & 0 & NO & $L R H+L C$ \\
\hline 6 & 2019.05 .28 & 205 & 100 & 0 & NO & $\mathrm{LRH}+\mathrm{LC}$ \\
\hline 7 & 2019.07 .23 & 285 & 250 & 0 & NO & $L W R+L C$ \\
\hline 8 & 2019.10 .11 & 145 & 50 & 0 & NO & LLLH \\
\hline 9 & 2019.10 .17 & 235 & 50 & 0 & NO & $L L H+L C$ \\
\hline 10 & 2019.10 .22 & 160 & 20 & 0 & NO & LWR \\
\hline 11 & 2019.10 .23 & 580 & 800 & 2 & NO & LMH \\
\hline 12 & 2019.11 .28 & 190 & 30 & 0 & NO & LLLH \\
\hline 13 & 2019.11 .28 & 235 & 150 & 0 & NO & LWR \\
\hline
\end{tabular}

LWR: laparoscopic wedge resection; LRH: laparoscopic right hepatectomy; LLLH: laparoscopic left lateral hepatectomy; LLH: laparoscopic left hepatectomy; LMH: laparoscopic midlobe hepatectomy; LC: laparoscopic cholecystectomy.

uncontrollable massive haemorrhage caused by the peripheral small vessels that were constantly torn during separation from the firm lesion. This case shows that this minimally invasive surgical approach may involve some technical difficulties in practice.

Several published case reports on laparoscopic treatment for hepatic $\mathrm{AE}$ published successful results with this technique $[6,10,18]$. They did not propose the selection criteria for AE treatment by laparoscopy due to the limited number of patients.

To the best of our knowledge, this study reports the first successful attempt in the field of minimally invasive hepatectomy in more than 10 patients with hepatic AE. In our series, the results were promising, with a $100 \%$ survival rate and only one case having a complication above Clavien-Dindo grade III, which is acceptable. The advantages of this minimally invasive surgical approach were fully illustrated by the enhanced recovery after surgery of patients and short-term hospitalisation. Of note, it is important to develop specific surgical plans according to the actual situation of the patient. For example, although the fifth patient's AE lesion was located in the right anterior lobe, we performed right half liver resection because of a $\mathrm{CE}$ cyst in the right posterior lobe simultaneously. In this way, the $\mathrm{AE}$ lesion and $\mathrm{CE}$ cyst could be removed simultaneously, effectively avoiding repeat surgery. In addition, the procedure for resecting a lesion in the middle liver lobe is more difficult because it is equivalent to the simultaneous completion of 
Table 3. Postoperative and follow-up information.

\begin{tabular}{|c|c|c|c|c|c|c|c|}
\hline Case & Eating $(d)$ & Emission $(d)$ & Tube $(d)$ & PHS $(d)$ & $\begin{array}{l}\text { Postoperative } \\
\text { complications }\end{array}$ & $\begin{array}{c}\text { Follow-up } \\
\text { (months) }\end{array}$ & $\overline{\text { Recurrence }}$ \\
\hline 1 & 1 & 1 & 6 & 7 & None & 30 & $\mathrm{NO}$ \\
\hline 2 & 1 & 3 & 21 & 14 & Acute liver failure & 27 & NO \\
\hline 3 & 1 & 1 & 5 & 6 & None & 21 & NO \\
\hline 4 & 3 & 3 & 9 & 9 & None & 20 & $\mathrm{NO}$ \\
\hline 5 & 2 & 3 & 3 & 6 & None & 20 & NO \\
\hline 6 & 1 & 1 & 4 & 5 & None & 15 & NO \\
\hline 7 & 1 & 2 & 14 & 7 & Hydrops & 13 & NO \\
\hline 8 & 1 & 1 & 3 & 7 & None & 10 & NO \\
\hline 9 & 1 & 1 & 4 & 6 & None & 10 & NO \\
\hline 10 & 1 & 1 & 6 & 8 & None & 10 & $\mathrm{NO}$ \\
\hline 11 & 1 & 3 & 8 & 10 & None & 10 & $\mathrm{NO}$ \\
\hline 12 & 1 & 1 & 3 & 4 & None & 9 & NO \\
\hline 13 & 1 & 1 & 4 & 5 & None & 9 & NO \\
\hline
\end{tabular}

PHS: postoperative hospital stay.

two hepatectomies. Therefore, we do not recommend attempting this approach for inexperienced surgical teams. Interestingly, all patients in this study did not take albendazole tablets regularly after surgery, but no relapse case was observed at 9-30 months follow-up.

With regard to the surgical indications of $\mathrm{LH}$ for $\mathrm{AE}$ treatment, we propose preliminary selective criteria (Fig. 2): (1) The patient's cardiopulmonary function and general condition can tolerate laparoscopic surgery. (2) Preoperative liver function is Child-Pugh grade A or B. (3) According to the WHO-IWGE classification criteria, the AE stage should be P1N0M0/P2N0M0. (4) The single AE lesion diameter should be $\leq 10 \mathrm{~cm}$. (5) Multiple $\mathrm{AE}$ lesions should all be located in the same half-liver. (6) The lesion does not adhere to the surrounding tissue. In addition to the above conditions, when the single lesion diameter exceeds $10 \mathrm{~cm}$ and/or the lesion is adherent to the surrounding tissue but no dense as armor, the surgical team should make the choice whether to perform LH according to the actual situation.

Although the results of our trial were encouraging, with only one patient experiencing a complication above ClavienDindo grade III and zero hospital mortality, we still consider that this study has some shortcomings. Firstly, the number of cases included was relatively small. Secondly, it is difficult to make an objective scientific evaluation of the superiority and inferiority of LH for AE treatment due to lacking direct comparison with classic open surgery. Therefore, further comparative studies with classical open hepatectomy are needed.

Finally, clinical practice guidelines have validated $\mathrm{LH}$ safety and feasibility, but we still considered that LH treatment for hepatic AE should be performed within institutions with experience in liver surgery.

In conclusion, the results of our preliminary study showed that LH is safe and feasible for radical treatment of hepatic AE. It can eliminate the whole $\mathrm{AE}$ lesion with a minimal wound. Strict patient selection and experienced surgical teams are key to successful surgery. The advantages of this technique for AE treatment need to be compared further with the classical open approach.

\section{Conflict of interest}

There are no competing interests.

Acknowledgements. This work was supported by the Natural Science Foundation of Xinjiang Uyghur Autonomous Region (No. 2017D01C322).

\section{References}

1. Aji T, Dong JH, Shao YM, Zhao JM, Li T, Tuxun $T$, Shalayiadang P, Ran B, Jiang TM, Zhang RQ, He YB, Huang JF, Wen H. 2018. Ex vivo liver resection and autotransplantation as alternative to allotransplantation for end-stage hepatic alveolar echinococcosis. Journal of Hepatology, 69, $1037-1046$.

2. Ambregna S, Koch S, Sulz MC, Gruner B, Ozturk S, Chevaux JB, Sulima M, de Gottardi A, Napoleon B, Abergel A, Bichard P, Boytchev I, Deprez P, Dumortier J, Frossard JL, Kull E, Meny B, Moradpour D, Prat F, Vanbievliet G, Thevenot T, Vuitton DA, Bresson-Hadni S, Vuitton L. 2017. A European survey of perendoscopic treatment of biliary complications in patients with alveolar echinococcosis. Expert Review of Antiinfective Therapy, 15, 79-88.

3. Bresson-Hadni S, Delabrousse E, Blagosklonov O, Bartholomot B, Koch S, Miguet JP, Mantion GA, Vuitton DA. 2006. Imaging aspects and non-surgical interventional treatment in human alveolar echinococcosis. Parasitology International, 55, S267.

4. Brunetti E, Kern P, Vuitton DA. 2010. Expert consensus for the diagnosis and treatment of cystic and alveolar echinococcosis in humans. Acta Tropica, 114, 1-16.

5. Chinese Doctor Association, Chinese College of Surgeons (CCS), Chinese Committee for Hadytidology (CCH). 2019. Expert consensus on diagnosis and treatment of hepatic cystic and alveolar echinococcosis (2019 edition). Chinese Journal of Digestive Surgery, 18, 711-721.

6. Kawamura N, Kamiyama T, Sato N, Nakanishi K, Yokoo H, Kamachi H, Tahara M, Yamaga S, Matsushita M, Todo S. 2011. Long-term results of hepatectomy for patients with alveolar echinococcosis: a single-center experience. Journal of the American College of Surgeons, 212, 804-812. 
7. Kuster T, Stadelmann B, Rufener R, Risch C, Muller J, Hemphill A. 2015. Oral treatments of Echinococcus multilocularis-infected mice with the antimalarial drug mefloquine that potentially interacts with parasite ferritin and cystatin. International Journal of Antimicrobial Agents, 46, 546-551.

8. McManus DP, Gray DJ, Zhang W, Yang Y. 2012. Diagnosis, treatment, and management of echinococcosis. British Medical Journal, 344, e3866.

9. Rufener R, Ritler D, Zielinski J, Dick L, da Silva ET, da Silva AA, Joekel DE, Czock D, Goepfert C, Moraes AM, de Souza MVN, Muller J, Mevissen M, Hemphil A, LundstromStadelmann B. 2018. Activity of mefloquine and mefloquine derivatives against Echinococcus multilocularis. International Journal for Parasitology Drugs \& Drugs Resistance, 8, 331-340.

10. Salm LA, Lachenmayer A, Perrodin SF, Candinas D, Beldi G. 2019. Surgical treatment strategies for hepatic alveolar echinococcosis. Food and Waterborne Parasitology, 12, e00050.

11. Stadelmann B, Kuster T, Scholl S, Barna F, Kropf C, Keiser J, Boykin DW, Stephens CE, Hemphill A. 2011. In vitro efficacy of dicationic compounds and mefloquine enantiomers against Echinococcus multilocularis metacestodes. Antimicrobial Agents and Chemotherapy, 55, 4866-4872.

12. Tamarozzi F, Vuitton L, Brunetti E, Vuitton DA, Koch S. 2014. Non-surgical and non-chemical attempts to treat echinococcosis: Do they work? Parasite, 21, 75.
13. Vuitton DA, Bresson-Hadni S. 2014. Alveolar echinococcosis: evaluation of therapeutic strategies. Expert Opinion on Orphan Drugs, 2, 67-86.

14. Vuitton DA, Azizi A, Richou C, Vuitton L, Blagosklonov O, Delabrousse E, Mantion GA, Bresson-Hadni S. 2016. Current interventional strategy for the treatment of hepatic alveolar echinococcosis. Expert Review of Anti-infective Therapy, 14, 1179-1194.

15. Vuitton DA, McManus DP, Rogan MT, Romig T, Gottstein B, Naidich A, Tuxun T, Wen H, Menezes da Silva A. 2020. International consensus on terminology to be used in the field of echinococcoses. Parasite, 27, 41.

16. Wen H, Dong JH, Zhang JH, Duan WD, Zhao JM, Liang YR, Shao YM, Ji XW, Tai QW, Li T, Gu H, Tuxun T, He YB, Huang JF. 2016. Ex vivo liver resection and autotransplantation for end-stage alveolar echinococcosis: a case series. American Journal of Transplantation, 16, 615-624.

17. Wen H, Vuitton L, Tuxun T, Li J, Vuitton DA, Zhang WB, McManus DP. 2019. Echinococcosis: advances in the 21st Century. Clinical Microbiology Reviews, 32, e00075-18.

18. Zhao ZM, Yin ZZ, Meng Y, Jiang N, Ma ZG, Pan LC, Tan XL, Chen X, Liu R. 2020. Successful robotic radical resection of hepatic echinococcosis located in posterosuperior liver segments. World Journal of Gastroenterology, 26, 2831-2838.

Cite this article as: Wan L, Ran B, Aji T, Shalayiadang P, Jiang T, Shao Y \& Wen H. 2021. Laparoscopic hepatectomy for the treatment of hepatic alveolar echinococcosis. Parasite 28, 5.

\section{PARASTE}

An international open-access, peer-reviewed, online journal publishing high quality papers on all aspects of human and animal parasitology

Reviews, articles and short notes may be submitted. Fields include, but are not limited to: general, medical and veterinary parasitology; morphology, including ultrastructure; parasite systematics, including entomology, acarology, helminthology and protistology, and molecular analyses; molecular biology and biochemistry; immunology of parasitic diseases; host-parasite relationships; ecology and life history of parasites; epidemiology; therapeutics; new diagnostic tools.

All papers in Parasite are published in English. Manuscripts should have a broad interest and must not have been published or submitted elsewhere. No limit is imposed on the length of manuscripts.

Parasite (open-access) continues Parasite (print and online editions, 1994-2012) and Annales de Parasitologie Humaine et Comparée (1923-1993) and is the official journal of the Société Française de Parasitologie. 